\title{
Occupational challenges of young adult patients with congenital heart disease
}

\author{
M. A. Sluman • S. de Man • B. J. M. Mulder • J. K. Sluiter
}

Published online: 22 February 2014

(C) The Author(s) 2014. This article is published with open access at Springerlink.com

\begin{abstract}
Background Despite improved survival of adults with congenital heart disease (CHD), higher rates of unemployment and work-related problems are seen, especially among younger adults. This study was performed to gain insight into current barriers and facilitating experiences at work among young adult patients with CHD.

Methods This qualitative study consisted of semi-structured face-to-face interviews, based on a self-constructed model from several existing models, which were held among outpatients with CHD from a large tertiary referral centre. Verbatim transcribed audio-taped data were analysed using a directed model-based content analysis approach.
\end{abstract}

All authors take full responsibility for all aspects of the reliability and freedom from bias of the data presented and their discussed interpretation.

The questions can be answered after the article has been published in print. You have to $\log$ in to: www.cvoi.nl.

M. A. Sluman · S. de Man • B. J. M. Mulder

Department of Cardiology, Academic Medical Center, Amsterdam, the Netherlands

M. A. Sluman • B. J. M. Mulder

Interuniversity Cardiology Institute of the Netherlands, Utrecht, the Netherlands

S. de Man · J. K. Sluiter

Coronel Institute of Occupational Health, Academic Medical Center,

Amsterdam, the Netherlands

M. A. Sluman

Department of Cardiology, Academic Medical Center, Room

B2-215, Meibergdreef 9, 1105 AZ Amsterdam, the Netherlands

B. J. M. Mulder ( $\square)$

Department of Cardiology, Academic Medical Center, Room

B2-240, Meibergdreef 9, 1105 AZ Amsterdam, the Netherlands

e-mail: b.j.mulder@amc.uva.nl

URL: www.concor.net
Results Fifteen patients had been interviewed when data saturation was reached. Work was important for all participants. Several barriers and facilitating factors were identified. Barriers were mostly on physical aspects and lack of opportunities for recovery. Important facilitating factors were good relationships with colleagues and employer and having sufficient opportunities for recovery. Most of these factors are also seen among patients with other chronic diseases, but with a different priority. Conclusion This is the first study that has identified qualitative factors at work of young adult CHD patients. Work is important to them. Challenges are dealing with the physical barriers and getting enough support from colleagues. Specific coaching or a tailored group intervention could thereby be helpful. Future research should aim at the aetiology of problems and identifying patients who would benefit most from specific coaching.

Keywords Congenital heart disease - Work - Employment . Qualitative research

\section{Introduction}

The number of patients with congenital heart disease (CHD) who reach adulthood has grown extensively over the last decades. Due to the great development in techniques, CHD has more and more become a chronic disease [1,2]. Aspects such as education and work therefore become increasingly important and are sometimes even more important contributors to quality of life than health status itself [3, 4].

Socio-economic outcomes among adults with chronic diseases are far from optimal, with unemployment rates nearly twice as high as among healthy individuals [3]. Several studies have identified factors contributing to maintaining work among different kinds of chronic diseases such as rheumatoid arthritis, asthma and ischaemic heart disease [3,5]. Previous studies have shown that most patients with CHD are able to work, 
although higher rates of unemployment are seen in most observational studies compared with the general population, especially among severe CHD [6-10]. Physical problems are often reported as a reason [11]. A recent study from our group showed that patients with (even mild) CHD, especially patients under the age of 40 years, were more often unemployed, worked less hours and had lower incomes than their healthy peers [8]. Although socio-economic outcomes in CHD need to improve, specific information on the experiences and needs of employees with CHD at work is lacking. Therefore, this study aims at exploring barriers and facilitating factors adults with CHD experience at work. This will help us gain better understanding and suggest possible strategies on how to intervene.

\section{Methods}

Qualitative research was conducted to explore experiences at work among young adult patients with CHD through semistructured in-depth face-to-face interviews [12]. The study followed the ethical recommendations of the Declaration of Helsinki [13]. COREQ criteria were used as the fundament for reporting the data [14].

\section{Instruments and procedures}

The structure of our self-developed interview was based on a model we constructed from several existing models, based on a theoretical framework (Table 1). This framework consisted of a combination of the classical 'Workload - work capacity model' [15], the 'Effort and recuperation model' [16], the 'Structure of the psychosocial work environment model' of the QEEW (Questionnaire Experience and Evaluation of Work) [17] and information from qualitative studies in other patient populations . Barriers that were described in the literature were mostly on physical job demands, low social support and fatigue [5]. We added specific items for patients with $\mathrm{CHD}$ that are known from the literature, such as the feeling of being different, revealing or hiding the $\mathrm{CHD}$ and coping with the disease and the healthcare system $[18,19]$.

The interviews consisted of questions on demographic items, including information about education and the contents of the patient's current work, working times, type of contract and job choice. Besides this, experienced barriers as well as facilitating factors at work in relation to the CHD were the main subject of the interview. During the interview, participants were encouraged to speak openly to gain more in-depth information. To improve reliability, the interviewer recapitulated important parts of the answers given during the interview for member checking. A pilot interview was performed to pre-test the usability of the interview with feedback from an experienced interviewer. The interviewer (SdM) had no relations with the selected patients and was not directly involved in their care.
Patients were screened between February and April 2012 through information in their medical files. All patients were treated in one large outpatient cardiology clinic from a tertiary referral centre in the Netherlands. Patients were eligible if they had known CHD, they were in paid work or had been in paid work in the past 6 months (following the definition of Statistics Netherlands), had a full understanding of the Dutch language and were aged between 20 and 35 years. Patients with mental retardation or severe comorbidity were excluded. Heterogeneity in CHD severity, age, gender, jobs and clinical classification according to the New York Heart Association (NYHA) was intended. CHD severity was based on a consensus-based classification scheme [20].

An information letter was sent to selected patients in advance. Patients were approached to participate after their regular appointment at the outpatients clinic. Informed consent was obtained verbally. All interviews were held in Dutch (the native language for both interviewer and interviewees) and were audio-taped. The interviews lasted between 18 and $56 \mathrm{~min}$ (mean duration $34 \mathrm{~min}$ ). All interviews but one were held in a private room of the outpatient clinic. One interview was, on request, held at the participant's home. In five interviews a partner or parent of the participant was present and able to contribute to the interview. All supported the patient's opinions.

\section{Data analysis}

All interviews were transcribed verbatim and analysed with the directed content analysis approach by two researchers (SdM and MS) [21]. This analysis approach consists of identifying meaningful text fragments, selective open coding and interpretation. Our own model was used as a frame for coding the data (Table 1). After coding, analyses were compared and differences were discussed until consensus was reached. To increase reliability of the analysis, three interviews were read and open coded by a third researcher (JS). Data saturation was checked during the process and reached after participant 14 . Negative case analyses consisted of discussion within the research team. Illustrative quotations were selected from different interviews by the research team. MAXqda 10 software [Kuckarts, Udo. Berlin, Germany] was used for analysis.

\section{Results}

Participants

In total, 15 patients were interviewed between April and May 2012. Twenty-four patients were preselected and asked to participate. Patients who did not participate did not have time (7 patients) or did not fulfil the criteria (2 patients did not work). 
Table 1 Theoretic model

\begin{tabular}{|c|c|c|c|c|}
\hline 1. Work factors & $\begin{array}{l}\text { 2. Possibility for work } \\
\text { adjustment }\end{array}$ & $\begin{array}{l}\text { 3. Work strain and } \\
\text { symptoms }\end{array}$ & $\begin{array}{l}\text { 4. Effect of } \\
\text { stressors }\end{array}$ & $\begin{array}{l}\text { 5. Work } \\
\text { capacity/processing } \\
\text { capacity }\end{array}$ \\
\hline $\begin{array}{l}\text { Job content } \\
\text { Physical load: B, F } \\
\text { Psychological load } \\
\text { Pace and quantity } \\
\text { Emotional load: F } \\
\text { Mental load } \\
\text { Formal operations } \\
\text { and proceedings and } \\
\text { responsibilities } \\
\text { Rules on working } \\
\text { methods, work pace, } \\
\text { resources, action } \\
\text { sequence and result } \\
\text { Versatility } \\
\text { Task variation } \\
\text { Learning } \\
\text { opportunities } \\
\text { Job conditions } \\
\text { Physical conditions } \\
\text { (e.g. climate): B } \\
\text { Chemical conditions } \\
\text { Biological conditions } \\
\text { Availability of tools: } \\
\text { F } \\
\text { Commuter traffic: B, } \\
\text { F } \\
\text { Conditions of } \\
\text { employment } \\
\text { Working hours and } \\
\text { breaks: B, F } \\
\text { Remuneration: B } \\
\text { Career opportunities: } \\
\text { B, F } \\
\text { Employment contract } \\
\text { Relations } \\
\text { Relationships with } \\
\text { colleagues: B, F } \\
\text { Relationships with } \\
\text { employer: B, F } \\
\text { Organisational } \\
\text { structure, control } \\
\text { Task information } \\
\text { Communication } \\
\text { Role conflict } \\
\text { Role ambiguity }\end{array}$ & $\begin{array}{l}\text { Job autonomy: B, F } \\
\text { Participation } \\
\text { Job control - } \\
\text { Recovery } \\
\text { possibilities } \\
\text { Internal recovery } \\
\text { possibilities: F } \\
\text { External recovery } \\
\text { possibilities: F } \\
\text { Recovery } \\
\text { possibilities } \\
\text { regarding work- } \\
\text { private life } \\
\text { balance: B, F }\end{array}$ & $\begin{array}{l}\text { Tension } \\
\text { Worrying } \\
\text { Emotional } \\
\text { reactions: B, F } \\
\text { Wellbeing } \\
\text { Reluctance } \\
\text { Involvement } \\
\text { Intentions of } \\
\text { leaving }\end{array}$ & & $\begin{array}{l}\text { Physical aspects: B } \\
\text { Cognitive aspects: } \\
\text { B } \\
\text { Emotional aspects: } \\
\text { B, F } \\
\text { Need for recovery }\end{array}$ \\
\hline
\end{tabular}

Eight patients were male and the mean age of the participants was 28 years (range 22-35 years). Demographic and work characteristics are described in Table 2. Three participants were not working or worked less hours due to recent surgery, but had been working in the past 6 months. With these participants, working experiences were discussed from the period before and after surgery. One patient with comorbidity was not excluded because he did not experience any 
Table 2 Demographic, work and clinical characteristics

\begin{tabular}{|c|c|c|c|c|c|c|c|c|}
\hline Participant & Sex & Age & Diagnosis & Severity & NYHA & Type of work & Operation, remaining defect & $\begin{array}{l}\text { Hrs } \\
\text { work/week }\end{array}$ \\
\hline 1 & $\mathrm{~F}$ & 23 & PS & Moderate & II & $\begin{array}{l}\text { Nursing } \\
\text { student }\end{array}$ & $\begin{array}{l}\text { Balloon pulmonary valvuloplasty at age } 9 \text {; remaining } \\
\text { mod. PR and PS }\end{array}$ & $38-40$ \\
\hline 2 & M & 26 & CoA, BAV & Moderate & I & Gardener & $\begin{array}{l}\text { Corrected through subclavian flap at age } 6 \text {; BAV with } \\
\text { good function }\end{array}$ & $45-54$ \\
\hline 3 & M & 29 & Supravalvular AS & Moderate & II & $\begin{array}{l}\text { Administrative } \\
\text { assistant }\end{array}$ & Corrected in childhood & 38 \\
\hline 4 & M & 22 & ToF & Moderate & I & Team leader & $\begin{array}{l}\text { Corrected at age of } 2 \text {; homograft at age } 22 \text {, remaining } \\
\text { mild PR and PS }\end{array}$ & 40 \\
\hline 5 & $\mathrm{~F}$ & 27 & Subvalvular AS & Moderate & I & PhD candidate & Mild AR and AS & 50 \\
\hline 6 & M & 29 & TGA & Severe & II & $\begin{array}{l}\text { Window } \\
\text { cleaner }\end{array}$ & $\begin{array}{l}\text { Arterial switch in first year; patch in RVOT because of } \\
\text { PS at age 20, remaining mod. PR; systemic LV with } \\
\text { good function }\end{array}$ & 21 \\
\hline 7 & M & 24 & ToF & Moderate & II & $\begin{array}{l}\text { Laboratory } \\
\text { technician }\end{array}$ & $\begin{array}{l}\text { Corrected in first year; homograft at age 17, remaining } \\
\text { mild PR and mod. PS }\end{array}$ & 32 \\
\hline 8 & $\mathrm{~F}$ & 27 & $\begin{array}{l}\text { BAV with sever } \\
\text { AS, dilated root }\end{array}$ & Moderate & II & $\begin{array}{l}\text { Day care } \\
\text { centre }\end{array}$ & Aortic root replacement at age 27 (recent) & 32 \\
\hline 9 & $\mathrm{~F}$ & 35 & $\begin{array}{l}\text { TGA, VSD, } \\
\text { overriding aorta }\end{array}$ & Severe & II & Hairdresser & $\begin{array}{l}\text { Arterial switch and closure of VSD at age } 2 \text {. Bentall } \\
\text { surgery because of severity. AR at age } 34 \text {. Decreased } \\
\text { LV and RV function }\end{array}$ & 25 \\
\hline 10 & $\mathrm{~F}$ & 32 & $\begin{array}{l}\text { Pulmonary atresia, } \\
\text { VSD }\end{array}$ & Severe & II & $\begin{array}{l}\text { Sales assistant } \\
\text { in parents' } \\
\text { fish shop }\end{array}$ & $\begin{array}{l}\text { Patch in RVOT at age } 2 \text {; closure of VSD at age } 4 \text {; severe } \\
\text { PR, PAH, ventricular tachycardia }\end{array}$ & 16 \\
\hline 11 & $\mathrm{~F}$ & 32 & $\begin{array}{l}\text { ccTGA, VSD, PS, } \\
\text { situs inversus, } \\
\text { dextrocardia }\end{array}$ & Severe & II & $\begin{array}{l}\text { Management } \\
\text { assistant }\end{array}$ & $\begin{array}{l}\text { VSD closure at age 3, pacemaker implantation due to } \\
\text { postoperative AV-block; balloon valvuloplasty; } \\
\text { systemic RV; mild PR, mod. PS }\end{array}$ & 15 \\
\hline 12 & M & 24 & $\begin{array}{l}\text { BAV with severe } \\
\text { AR }\end{array}$ & Mild & II & $\begin{array}{l}\text { Administrative } \\
\text { assistant }\end{array}$ & Bentall surgery at age 24 (recent) & 40 \\
\hline 13 & M & 28 & $\begin{array}{l}\text { Interrupted aortic } \\
\text { arch, VSD }\end{array}$ & Moderate & II & $\begin{array}{l}\text { Excavation } \\
\text { worker } \\
\text { (digger) }\end{array}$ & $\begin{array}{l}\text { Both corrected in first year; re-operation at age } 9 \text { with } \\
\text { Dacron bypass; bronchus obstruction from bypass at } \\
\text { age } 19\end{array}$ & 40 \\
\hline 14 & $\mathrm{~F}$ & 34 & $\begin{array}{l}\text { Tricuspid atresia, } \\
\text { VSD, ASD 2, } \\
\text { PS }\end{array}$ & Severe & II & Receptionist & $\begin{array}{l}\text { Palliated at age } 1 \text { by central aortic-pulmonic shunt, } \\
\text { Fontan surgery at age } 6 \text {, re-operated at age } 18 \text { and } 34 \\
\text { (recent) }\end{array}$ & 12 \\
\hline 15 & M & 26 & ASD 2 & Mild & I & $\mathrm{PhD}$ candidate & Surgical closure at age 2 . Remaining RV dilatation & 60 \\
\hline
\end{tabular}

Abbreviations: $F$ female, $M$ male, NYHA New York Heart Association classification, $P S$ pulmonary stenosis, $P R$ pulmonary regurgitation, $C o A$ coarctation of the aorta, $B A V$ bicuspid aortic valve, $A S$ aortic stenosis, $T o F$ tetralogy of Fallot, $A R$ aortic regurgitation, $T G A$ transposition of the great arteries, $R V O T$ right ventricular outflow tract, $L V$ left ventricle, $R V$ right ventricle, $P A H$ pulmonary arterial hypertension, $c c T G A$ congenitally corrected transposition of the great arteries, VSD ventricular septal defect, $A S D 2$ atrial septal defect type 2

limitations in his very demanding job and could therefore contribute important information. All participants attended at least secondary school. CHD had affected job choice in 5 participants. One participant performed a less physical job than he desired. The other 4 participants worked at a lower level than their educational level. Overall, work played an important role in the daily lives of all participants. Two participants, with mild and moderate CHD and NYHA I, experienced neither barriers nor facilitating factors at work that could be related to their CHD. Two participants with moderate CHD and NYHA I only experienced facilitating factors. The other 11 participants, all NYHA II but with ranging severity of CHD, experienced barriers and facilitating factors. No participants experienced only barriers. Tables 3 and 4 show all reported factors.

\section{Barriers}

The factors that were most frequently mentioned as barriers for work functioning are described below (Table 3).

\section{Physical aspects}

Participants often experienced the physical load of their work as too high, frequently leading to being less able to perform their job correctly. When working in a warm environment (heavier physical condition), multiple participants experienced problems of tiredness and complaints of dyspnoea. 
Table 3 Observed barriers

\section{Participants}

Barriers

$\begin{array}{lllllllllllllll}1 & 2 & 3 & 4 & 5 & 6 & 7 & 8 & 9 & 10 & 11 & 12 & 13 & 14 & 15\end{array}$

1. Work factors

Job content

Too much physical load

Job conditions

Heavy physical conditions (e.g. climate)

Negative effects of commuter traffic

Conditions of employment

Too much working hours, too little breaks

Too low remuneration

Too little career opportunities

Relations

Bad relationships with colleagues

Bad relationships with employer

2. Possibility for work adjustments

Too little job autonomy

Job control - Recovery possibilities

Too little recovery possibilities to preserve a good work-private life balance •

3. Work strain and symptoms

Tension

Negative emotional reactions

4. Negative effect of stressors

5. Work capacity/processing capacity

Negative physical aspects

Negative cognitive aspects

Negative emotional aspects

- = code observed in interview of participant; in bold = codes described in results

[...when my colleagues think it is just warm outside, I get really short of breath...] [Participant 6, P6]

\section{Lack of opportunity for recovery and processing capacity}

Most participants had problems with the balance between workload and the physical processing capacity they need for the job. Some of the participants experienced too little opportunity for recovery to preserve a good balance in work and private life, due to their increased need for recovery after work. This was mostly expressed as being fatigued during a working day. Fatigue was often more present after working several days in a row and was often experienced to be more present than in their healthy colleagues. A barrier mentioned by several participants was hours of work or working several days in a row. For some patients working full time was not possible, because they were not able to recover enough before returning to work. [....as the day progresses I get tired quite quickly. Even though I do seated and not very physical work, I get tired very quickly anyway.] [P7]

Some participants had a problem with the balance between workload and the cognitive processing capacity needed for the job. When workload was too high or processing capacity too low, participants experienced a decreased concentration ability during their workday.

[... than you will read a sentence two, three times. And you just do not get it, you just do not take it in fully. That is when I think: 'I'll have to leave it for another day.'] [P1]

\section{Relationships with employer}

Problems were experienced with employers when they could not understand the consequences of CHD for their employees. 
Therefore, some participants had been forced to transfer to a different job. Another patient had to arrange most of her rehabilitation at work after surgery without the support of her employer. For most participants these experiences were difficult to go through. Some participants experienced problems in their career opportunities. Applying for a job was difficult for some participants, partly due to physical limitations as well as experienced social disadvantage. Due to this, four participants worked at a lower level than their educational level. For most of the patients, the decision to tell the employer about their CHD had been difficult and well-considered.

[...At that time I noticed that it was difficult to apply... usually I was too honest about my CHD and then you would not get the job.] [... I can actually do a lot more, so that's a shame.] [P11]
Facilitating factors

Facilitating factors for work functioning with CHD are mentioned in Table 4 and the most important factors are described below.

\section{Physical aspects}

Some facilitating factors that were reported are not surprising in view of the barriers mentioned before. Participants benefitted, for example, from doing less physical work. Working at an office instead of having a demanding physical job, having better working hours or working less hours a day or a week or interrupting the work week by a day off were all mentioned as facilitating.

Table 4 Observed facilitating factors

\begin{tabular}{|c|c|c|c|c|c|c|c|c|c|c|c|c|c|c|}
\hline \multirow[t]{2}{*}{ Facilitating factors } & \multicolumn{14}{|c|}{ Participants } \\
\hline & 1 & 2 & 3 & 4 & 5 & 6 & 7 & 8 & 9 & 10 & 11 & 12 & 13 & 14 \\
\hline \multicolumn{15}{|l|}{ 1. Work factors } \\
\hline \multicolumn{15}{|l|}{ Job content } \\
\hline Right amount of physical load & & & $\bullet$ & $\bullet$ & & $\bullet$ & $\bullet$ & & & $\bullet$ & & & & - \\
\hline \multicolumn{15}{|l|}{ Psychological load } \\
\hline Positive emotional load & & & & & & & & & - & & & & & \\
\hline \multicolumn{15}{|l|}{ Job conditions } \\
\hline Availability of tools & & & & & & & & • & & & $\bullet$ & & & \\
\hline Positive effects of commuter traffic & & & & & & & $\bullet$ & & & & & & & $\bullet$ \\
\hline \multicolumn{15}{|l|}{ Conditions of employment } \\
\hline Right amount of working hours and breaks & & & & & & $\bullet$ & $\bullet$ & $\bullet$ & & $\bullet$ & $\bullet$ & & & \\
\hline Having career opportunities & & & & & & & & & & & $\bullet$ & & & $\cdot$ \\
\hline \multicolumn{15}{|l|}{ Relations } \\
\hline Good relationships with colleagues & & & - & $\bullet$ & $\bullet$ & $\bullet$ & - & $\bullet$ & - & - & $\bullet$ & & $\bullet$ & - \\
\hline Good relationships with employer & & & & $\bullet$ & $\bullet$ & • & • & & & & • & & & $\cdot$ \\
\hline \multicolumn{15}{|l|}{ 2. Possibility for work adjustments } \\
\hline Enough job autonomy & & & & & & $\bullet$ & • & & & $\bullet$ & $\bullet$ & & & \\
\hline \multicolumn{15}{|l|}{ Job control - Recovery possibilities } \\
\hline Enough internal recovery possibilities & $\bullet$ & & & & & $\bullet$ & $\bullet$ & $\bullet$ & $\bullet$ & - & & $\bullet$ & $\bullet$ & \\
\hline Enough external recovery possibilities & & & & & & • & $\bullet$ & $\bullet$ & & & • & & & $\bullet$ \\
\hline Enough recovery possibilities to preserve a good work-private life balance & & & & & & - & - & & & - & & - & & $\cdot$ \\
\hline \multicolumn{15}{|l|}{ 3. Work strain and symptoms } \\
\hline \multicolumn{15}{|l|}{ Tension } \\
\hline Positive emotional reactions & & & & & & & & & & & & & & - \\
\hline \multicolumn{15}{|l|}{ 4. - } \\
\hline \multicolumn{15}{|l|}{ 5. Work capacity/processing capacity } \\
\hline Positive emotional aspects & & & & & & & & & & & $\bullet$ & & • & \\
\hline
\end{tabular}

- = code observed in interview of participant; in bold = codes described in results 


\section{Opportunities for recovery}

Almost all factors in the theory model that were placed under possibility for work adjustment were recorded as important in facilitating. Job autonomy (being able to decide which task you do when and how) was observed as very important in several interviews.

[I work in a fish shop. But when it's warm we just don't fry the fish, since I already feel short of breath then.] [When I need to carry something, there is always someone who does it for me.] [P10]

Internal recovery opportunities, for example to be able to take a break or to rest during work when needed or being able to adjust the working environment, as well as external recovery opportunities, such as being able to recover during free time, for instance by taking a day off, were mentioned as helpful.

[If I indicate: 'Well, it is too much, I need 2 days off.' Then it is quite easily arranged.] [P7]

Having enough opportunity for recovery to preserve a good work-private life balance was also a returning subject. Participants needed more time, more than colleagues they believed, to recover from work in order to have enough time to live their private life's.

[...Sometimes when it's worse, you feel really tired for a while. Then they say: 'That's fine. Go home early or change your day'.] [P11]

\section{Relationships with colleagues and employer}

Good relationships with colleagues was experienced as a facilitating factor among almost all participants. Colleagues helped participants with their work or took over when needed. Participants also felt supported when colleagues showed interest in them and (the consequences of) their CHD. Involvement through a period of sick leave was considered very supporting. A good relationship with the employer was seen as facilitating, based on support and flexibility of the employer, for example by letting them perform less physical work or letting them work less or flexible hours. How easily employees could arrange to stay away from work for hospital visits was very different among participants.

Though having too few career opportunities was reported as a barrier, some participants experienced benefit from their CHD in getting a job. One participant for example was hired after applying for a vacancy specifically aimed at occupationally handicapped persons.

\section{Discussion}

This is the first study that has identified both barriers and facilitating factors at work among young adults with CHD. Important facilitating factors were good relationships with colleagues and having enough recovery possibilities. Barriers were mainly caused by physical aspects and too little opportunity for recovery.

Work is important in the daily lives of young adults with CHD, and it is influenced by their CHD. CHD affects job choices and work in many ways: from adjustments that have already been made to prevent possible future problems to having been forced to change jobs due to their illness. Even though some of the relatively young adults with CHD experienced no or few problems at work, the disease influenced job choice in several patients and a substantial number of them worked below their educational levels. Considering that average educational levels among people with CHD are already a little below the general population [8], this is a serious issue that can lead to loss of talent and labour forces.

Factors that are described by this population of young adults with CHD are partly in accordance with what is seen by other patients with chronic diseases [22], although their weight seems somewhat different. A lot of barriers that were found among employees with CHD can be summarised to be caused by physical aspects and recovery capabilities and opportunities. Fatigue, decreased concentration and exertional dyspnoea were mentioned most. In this population, specific pathways could play a role. A lot of late complications of CHD present with fatigue [23]. This may also be influenced by the use of certain medications. Furthermore, patients with CHD are at increased risk for neurological, psychological and cognitive damage through many pathophysiological ways, especially those with severe or cyanotic defects [24]. Whether this is due to brain damage or cognitive impairment by the treatment or the CHD itself or is caused by something else is as yet unknown. Especially among adults with CHD there is very little information about the relationship between possible neuro-cognitive damage and practical outcomes. However, this does not explain why several participants worked at a lower level than their educational level. Previous studies among healthy individuals have shown that the need for recovery during and after working time is a major predictor of psychosomatic symptoms, sleep problems, and complaints of emotional exhaustion. This could lead to a vicious circle of more fatigue and physical problems, even potentially leading to sick leave.

Significant facilitating factors were mostly about good relationships with colleagues and employers and about having a sense of control: experiencing opportunities to adjust how and when the work was performed and to preserve an optimal work-private life balance. In the facilitating factors we might find the key to the solution: flexibility in work conditions and 
arrangements for breaks as well as positive relationships with colleagues and employers seem essential. Varekamp et al. have looked at workplace problems and solutions for people with different kinds of chronic diseases and found that working less hours, working at home, a slower work pace and more job autonomy were most desired solutions by patients with chronic diseases [25]. Several studies also show that motivation, personal coping strategies and personality traits are important for work participation for employees with other chronic diseases [27]. Showing interest or active support is highly appreciated and necessary: a lot of people with CHD who are considered to be asymptomatic report problems on health questionnaires [26]. Previously reported experiences of young adults with CHD also pointed out that it is hard to strike a balance between being a patient or a 'regular' employee (being different or not) and that there is often some ambivalence about telling people about the CHD [19]. This issue was also brought up by several participants in this study.

The results of this study can be used to tailor a specific (group) self-management intervention program to support CHD patients in their work [27]. Previous studies on these kinds of intervention programs for other chronic diseases show a decrease in physical symptoms and fatigue and better coping strategies $[28,29]$. Specific coaching for patients should try to increase self-confidence, assertiveness and the sense of job control and thereby consist of acquiring skills in how to deal with specific physical symptoms, to increase job autonomy, focus on job motivation and give insight into personal coping strategies and personality traits that could be of influence. Given our results, it should also emphasise the importance of good relationships with colleagues and employer. Considering certain CHD-specific aspects, for example telling colleagues and employer about the CHD and dealing with specific physical symptoms, a specialised intervention program for CHD patients could fit all of these needs. For employers and career advisors, helping patients with CHD should focus on reducing high physical job demands, especially for patients with more severe defects, and offering possibilities to arrange adaptations in the workplace and work hours when needed.

\section{Study limitations}

Although qualitative research is relatively uncommon and unknown within the field of clinical cardiology, we believe this is the best way to gain a better understanding of this subject. In the interpretation, however, since this is a qualitative study, we must realise that explanations for the higher rates of unemployment or work-related problems or direct solutions are not to be expected.

A shortcoming of the study is that, in hindsight, heterogeneity in patients functional class was not completely reached. Only patients with NYHA I and II were interviewed and this may have underestimated the barriers for work among patients with CHD and a lesser functional status. On the other hand, no patients with mild CHD were included. A limitation that may also have underestimated the barriers is that by the inclusion criteria of having a job, people with potentially the most or most severe barriers could have been excluded. A strong aspect of this study is that data were gathered through the use of a specific model. This theoretical model could, due to its basics, therefore include all relevant factors in one model. Because participants were able to talk openly and because the directed content analysis approach was used, no factors seem to be overlooked.

\section{Conclusions}

It is important for CHD patients to arrange their work in such a way that it is possible for each specific employee to function properly. To achieve this, a committed employer and employee are required. Possibilities for making personal adjustments in tasks or schedules and a good relationship with colleagues and employer play a pivotal role here. Healthcare professionals should be more aware that CHD can lead to specific barriers in the workplace. Further research on the neurocognitive background and aetiology of problems of concentration and fatigue may improve these barriers on the work field for long-term survivors of CHD and may help develop specific intervention programs and identify patients who would benefit most.

\section{Grant support None.}

\section{Conflicts of interest None declared.}

Open Access This article is distributed under the terms of the Creative Commons Attribution License which permits any use, distribution, and reproduction in any medium, provided the original author(s) and the source are credited.

\section{References}

1. Mulder BJ. Epidemiology of adult congenital heart disease: demographic variations worldwide. Neth Heart J. 2012;20(12):505-8.

2. Verheugt CL, Uiterwaal CS, Grobbee DE, et al. Long-term prognosis of congenital heart defects: a systematic review. Int J Cardiol. 2008;131(1):25-32.

3. Detaille SI, Heerkens YF, Engels JA, et al. Common prognostic factors of work disability among employees with a chronic somatic disease: a systematic review of cohort studies. Scand J Work Environ Health. 2009;35(4):261-81.

4. Moons P, van Deyk, de Bleser, et al. Quality of life and health status in adults with congenital heart disease: a direct comparison with healthy counterparts. Eur J Cardiovasc Prev Rehabil. 2006;13(3): 407-13. 
5. Detaille SI, Haafkens JA, van Dijk FJ. What employees with rheumatoid arthritis, diabetes mellitus and hearing loss need to cope at work. Scand J Work Environ Health. 2003;29(2):134-42.

6. Kamphuis M, Vogels T, Ottenkamp J, et al. Employment in adults with congenital heart disease. Arch Pediatr Adolesc Med. 2002;156(11):1143-8.

7. Crossland DS, Jackson SP, Lyall R, et al. Employment and advice regarding careers for adults with congenital heart disease. Cardiol Young. 2005;15(4):391-5.

8. Zomer AC, Vaartjes I, Uiterwaal CS, et al. Social burden and lifestyle in adults with congenital heart disease. Am J Cardiol. 2012;109(11):1657-63.

9. van Rijen EH, Utens EM, Roos-Hesselink JW, et al. Psychosocial functioning of the adult with congenital heart disease: a 20-33 years follow-up. Eur Heart J. 2003;24(7):673-83.

10. Kamphuis M, Verloove-Vanhorick SP, Vogels T, et al. Diseaserelated difficulties and satisfaction with level of knowledge in adults with mild or complex congenital heart disease. Cardiol Young. 2002;12(3):266-71.

11. Ladouceur M, Iserin L, Cohen S, et al. Key issues of daily life in adults with congenital heart disease. Arch Cardiovasc Dis. 2013;106(6-7):404-12.

12. Fossey E, Harvey C, McDermott F, et al. Understanding and evaluating qualitative research. Aust N Z J Psychiatr. 2002;36(6):717-32.

13. World Medical Association. World Medical Association Declaration of Helsinki. Ethical principles for medical research involving human subjects. JAMA. 2013;310(20):2191-4.

14. Tong A, Sainsbury P, Craig J. Consolidated criteria for reporting qualitative research (COREQ): a 32-item checklist for interviews and focus groups. Int J Qual Health Care. 2007;19(6):349-57.

15. van Dijk FJH, van Dormolen M, Kompier MAJ, et al. Revaluation model workload work capacity. T Soc Gezondheidsz. 1990;68:3-10.

16. de Jonge J, Zijlstra FRH, Sluiter JK. Not now...! About recuperation and recuperation strategies at work. Gedrag en Organisatie. 2010;23(4):259-74.

17. van Veldhoven M. Manual QEEW. 1997.
18. Schoormans D, Sprangers MA, Budts W, Mulder BJ, Apers S, Moons P. Perceived health is partially associated with the symptomatological profile in patients with benign and severe conditions: the case of congenital heart disease. Qual Life Res. 2013;22(6):1295304.

19. Berghammer M, Dellborg M, Ekman I. Young adults experiences of living with congenital heart disease. Int J Cardiol. 2006;110(3):340-7.

20. Warnes CA, Liberthson R, Danielson GK, et al. Task force 1: the changing profile of congenital heart disease in adult life. J Am Coll Cardiol. 2001;37(5):1170-5.

21. Hsieh HF, Shannon SE. Three approaches to qualitative content analysis. Qual Health Res. 2005;15(9):1277-88.

22. Sluiter JK, van der Beek AJ, Frings-Dresen MH. The influence of work characteristics on the need for recovery and experienced health: a study on coach drivers. Ergonomics. 1999;42(4):573-83.

23. Baumgartner H, Bonhoeffer P, de Groot NM, et al. ESC Guidelines for the management of grown-up congenital heart disease (new version 2010). Eur Heart J. 2010;31(23):2915-57.

24. Karsdorp PA, Everaerd W, Kindt M, et al. Psychological and cognitive functioning in children and adolescents with congenital heart disease: a meta-analysis. J Pediatr Psychol. 2007;32(5):527-41.

25. Varekamp I, van Dijk FJH. Workplace problems and solutions for employees with chronic diseases. Occup Med Oxf. 2010;60(4):28793.

26. Berghammer M, Karlsson J, Ekman I, Eriksson P, Dellborg M. Selfreported health status (EQ-5D) in adults with congenital heart disease. Int J Cardiol. 2013;165(3):537-43.

27. Schoormans D, Mulder BJ, Sprangers MA. Letter by Schoormans et al. regarding article, "recommendations for improving the quality of interdisciplinary care of grown-up with congenital heart disease (GUCH)". Int J Cardiol. 2011;151(1):121.

28. Lorig KR, Holman H. Self-management education: history, definition, outcomes, and mechanisms. Ann Behav Med. 2003;26(1):1-7.

29. Smeulders ES, van Haastregt JC, Ambergen T, et al. Nurse-led selfmanagement group programme for patients with congestive heart failure: randomized controlled trial. J Adv Nurs. 2010;66(7):1487-99.

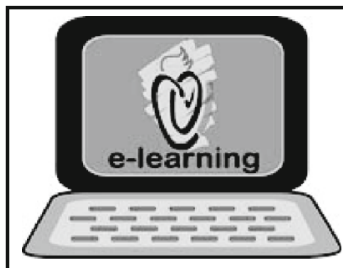

\section{CVOI E-learning formula!}

This is the CVOI e-learning article. The author has prepared 10 questions which are available through the website of the Cardiovascular Educational Institute (CVOI). Please follow the instructions below.

After finishing the questions you will be asked to fill in your name, hospital and e-mail address; then press the button 'verzenden'.

When 6 out of the 10 questions are answered correctly, you acquire 1 accreditation point granted by the Quality Committee of the Netherlands Society of Cardiology (NVVC). The acquired point will be credited to your personal file in the GAIA system. You will also receive an e-mail with all the correct answers.

Over a period of one year 10 e-learning articles will appear in 10 subsequent NHJ editions. In each edition the e-learning article will be recognisable by a special icon. On an annual basis you can collect 10 accreditation points. The accreditation points are credited in the GAIA system by the CVOI.

If you need additional information, please contact the CVOI by e-mail: cvoi@cvoi.org or by phone: 030-2345001.

E.E. van der Wall

Chief editor NHJ
K.B. Schick

Coordinator CVOI 